\title{
Efficacy of everolimus with exemestane versus exemestane alone in Asian patients with HER2-negative, hormone-receptor-positive breast cancer in BOLERO-2
}

\author{
Shinzaburo Noguchi • Norikazu Masuda • Hiroji Iwata · Hirofumi Mukai · Jun Horiguchi • Puttisak Puttawibul • \\ Vichien Srimuninnimit • Yutaka Tokuda • Katsumasa Kuroi • Hirotaka Iwase • Hideo Inaji • Shozo Ohsumi • \\ Woo-Chul Noh · Takahiro Nakayama $\cdot$ Shinji Ohno $\cdot$ Yoshiaki Rai $\cdot$ Byeong-Woo Park $\cdot$ Ashok Panneerselvam • \\ Mona El-Hashimy • Tetiana Taran • Tarek Sahmoud • Yoshinori Ito
}

Received: 25 September 2012/ Accepted: 8 January 2013/Published online: 13 February 2013

(C) The Author(s) 2013. This article is published with open access at Springerlink.com

\begin{abstract}
Background The addition of mTOR inhibitor everolimus (EVE) to exemestane (EXE) was evaluated in an international, phase 3 study (BOLERO-2) in patients with hormone-receptor-positive $\left(\mathrm{HR}^{+}\right)$breast cancer refractory to letrozole or anastrozole. The safety and efficacy of anticancer treatments may be influenced by ethnicity (Sekine et al. in Br J Cancer 99:1757-62, 2008). Safety and efficacy results from Asian versus non-Asian patients in BOLERO2 are reported.
\end{abstract}

Please note that although partial results were presented at the 2012 ASCO Annual Meeting, this article is an original work that has not been published elsewhere, and all authors agree to its submission.

S. Noguchi $(\bowtie) \cdot$ T. Nakayama

Department of Breast and Endocrine Surgery,

Osaka University, Osaka, Japan

e-mail: noguchi@onsurg.med.osaka-u.ac.jp

N. Masuda

Department of Surgery, Breast Oncology, National Hospital

Organization, Osaka National Hospital, Osaka, Japan

H. Iwata

Department of Breast Oncology, Aichi Cancer Center Hospital,

Nagoya, Japan

H. Mukai

Department of Breast Oncology, National Cancer Center

Hospital East, Kashiwa, Japan

J. Horiguchi

Breast and Endocrine Surgery, Gunma University Hospital,

Maebashi, Japan

P. Puttawibul

Songklanagarind Hospital, Faculty of Medicine,

Prince of Songkla University, Songkhla, Thailand
Methods Patients were randomized (2:1) to $10 \mathrm{mg} / \mathrm{day}$ $\mathrm{EVE}+\mathrm{EXE}$ or placebo $(\mathrm{PBO})+$ EXE. Primary endpoint was progression-free survival (PFS). Secondary endpoints included overall survival, response rate, clinical benefit rate, and safety.

Results Of 143 Asian patients, 98 received EVE + EXE and 45 received $\mathrm{PBO}+\mathrm{EXE}$. Treatment with EVE + EXE significantly improved median PFS versus $\mathrm{PBO}+\mathrm{EXE}$ among Asian patients by $38 \%(\mathrm{HR}=0.62$; $95 \%$ CI, 0.41-0.94). Median PFS was also improved among non-Asian patients by $59 \%(\mathrm{HR}=0.41 ; 95 \% \mathrm{CI}$, 0.33-0.50). Median PFS duration among EVE-treated Asian patients was 8.48 versus 4.14 months for PBO + EXE, and 7.33 versus 2.83 months, respectively, in non-Asian patients. The most common grade 3/4 adverse

V. Srimuninnimit

Siriraj Hospital, Mahidol University, Bangkok, Thailand

Y. Tokuda

Department of Breast and Endocrine Surgery,

Tokai University Hospital, Isehara, Japan

K. Kuroi

Department of Surgery, Tokyo Metropolitan Cancer

and Infectious Diseases Center Komagome Hospital,

Tokyo, Japan

H. Iwase

Department of Breast and Endocrine Surgery,

Kumamoto University, Kumamoto, Japan

H. Inaji

Department of Breast and Endocrine Surgery,

Osaka Medical Center for Cancer and Cardiovascular Diseases,

Osaka, Japan 
events (stomatitis, anemia, elevated liver enzymes, hyperglycemia, and dyspnea) occurred at similar frequencies in Asian and non-Asian patients. Grade 1/2 interstitial lung disease occurred more frequently in Asian patients. Quality of life was similar between treatment arms in Asian patients.

Conclusion Adding EVE to EXE provided substantial clinical benefit in both Asian and non-Asian patients with similar safety profiles. This combination represents an improvement in the management of postmenopausal women with $\mathrm{HR}^{+} / \mathrm{HER} 2^{-}$advanced breast cancer progressing on nonsteroidal aromatase inhibitors, regardless of ethnicity.

Keywords Advanced breast cancer - Endocrine resistance $\cdot$ Everolimus $\cdot$ Exemestane $\cdot$ Progression-free survival

\section{Introduction}

Worldwide, breast cancer is the most common malignancy in women and one of the leading causes of cancer deaths [1-3]. Incidence of breast cancer in Asia is increasing [3]. In Asia, as in Western countries, treatment approaches for breast cancer typically follow National Comprehensive Cancer Network [4] and St. Gallen guidelines. For postmenopausal patients with hormone-receptor-positive $\left(\mathrm{HR}^{+}\right)$advanced breast cancer, aromatase inhibitors (steroidal or nonsteroidal) are the standard initial treatment [4]. Even so, most patients are unresponsive to initial treatment or acquire resistance. Other treatment options include estrogen receptor (ER) antagonists (e.g., tamoxifen) and ER downregulators (e.g., fulvestrant). These treatment options provide limited clinical benefit once endocrine resistance develops (especially after aromatase inhibitor therapy), and survival is poor [5]. New treatment options that can offer patients with advanced breast cancer the hope of overcoming resistance and that can prolong the time of

S. Ohsumi

Department of Breast Oncology, NHO Shikoku Cancer Center,

Matsuyama, Japan

W.-C. Noh

Department of Surgery, Korea Cancer Center Hospital, Seoul, Korea

\section{S. Ohno}

Department of Breast Oncology,

National Kyushu Cancer Center, Fukuoka, Japan

\section{Y. Rai}

Department of Breast Surgery, Hakuaikai Sagara Hospital,

Kagoshima, Japan effectiveness of endocrine therapy and delay chemotherapy are needed.

Hyperactivation of the mammalian target of rapamycin (mTOR) pathway is associated with breast cancer progression and with the development of endocrine resistance [6]. Aberrations in phosphatidylinositol 3-kinase (PI3K)/ mTOR pathway protein expression are also associated with poor prognosis in $\mathrm{HR}^{+}$breast cancer [7]. However, in vitro and in vivo data indicate that mTOR inhibitors can inhibit cell proliferation and restore sensitivity to fulvestrant, letrozole, and tamoxifen [8-11].

Everolimus (Afinitor ${ }^{\circledR}$, Novartis) is an orally active mTOR inhibitor. It is approved for the treatment of patients with progressive neuroendocrine tumors of pancreatic origin, advanced renal cell carcinoma, and subependymal giant cell astrocytoma associated with tuberous sclerosis [12]. Recently, everolimus (EVE) was also approved in combination with exemestane (EXE) for use in the USA and the 27 European Union member states, plus Iceland and Norway, and in Mexico, Argentina, and other Latin American countries, for the treatment of postmenopausal patients with $\mathrm{HR}^{+}$breast cancer whose disease has progressed during or after nonsteroidal aromatase inhibitor therapy. This approval was based on outcomes from BOLERO2. In this phase 3 study, EVE + EXE improved progressionfree survival (PFS) compared with EXE + placebo (PBO; median PFS $=7.8$ months vs 3.2 months, respectively; hazard ratio $[\mathrm{HR}]=0.45 ; P<0.0001)[12]$.

Variations in the pharmacodynamics and pharmacokinetics of anticancer agents can be attributed in part to ethnic differences, potentially resulting in alterations of their safety and efficacy profiles [13]. In fact, some studies of targeted therapies have shown that variability in safety and efficacy is associated with patient ethnicity [14]. To ensure an optimal treatment response is balanced with a manageable safety profile, the potential inter-ethnic differences in anticancer drug effects should be considered [13]. Treatment for lung cancer using the epidermal growth factor inhibitor gefitinib, for example, is more effective in Asian patients than in patients of other ethnicities [15].

B.-W. Park

Department of Surgery, Yonsei University College of Medicine, Seoul, Korea

A. Panneerselvam · M. El-Hashimy · T. Taran · T. Sahmoud Department of Global Oncology Development,

Novartis Pharmaceuticals Corporation, East Hanover, NJ, USA

Y. Ito

Department of Medical Oncology, Breast Oncology Center,

Cancer Institute Hospital, Japanese Foundation for Cancer

Research, Tokyo, Japan 
The incidence of interstitial lung disease (ILD) is also more prevalent in Asian patients treated with gefitinib monotherapy than in those of other ethnicities [15]. ILD is one of the relatively common, serious adverse events (AEs) associated with molecular targeted anticancer therapies, and treatment with EVE has been associated with ILD [16, 17]. Thus, it is important to compare the frequency of AEs, including ILD, induced by EVE in both Asian and nonAsian patients.

To determine whether patient ethnicity has an effect on the efficacy and safety of EVE + EXE, we performed an analysis in Asian versus non-Asian patients with $\mathrm{HR}^{+}$ advanced breast cancer in BOLERO-2 after a median follow-up of 18 months.

\section{Patients and methods}

The BOLERO-2 study is an international, phase 3, multicenter, randomized, double-blind, placebo-controlled trial (ClinicalTrials.gov identifier NCT00863655). The protocol and results for the entire study have been reported $[16,18]$. Post hoc analyses of the data from Asian patients (who selected Asian as their race at randomization) and nonAsian patients included in BOLERO-2 are reported herein.

\section{Patients}

Patients were postmenopausal women with metastatic or locally advanced, estrogen receptor-positive $\left(\mathrm{ER}^{+}\right)$human epidermal growth factor receptor-2 nonamplified (HER2 ${ }^{-}$) breast cancer that had recurred or progressed during or after letrozole or anastrozole therapy as described previously [16]. This study was conducted in accordance with the Declaration of Helsinki, in agreement with the institutional review board at each participating center, in accordance with Good Clinical Practice and applicable local regulations. Every patient provided written informed consent.

Study design

Patients were randomized $(2: 1)$ to EVE (10 mg/day) + EXE (25 mg/day) or PBO + EXE (25 mg/day). Randomization was stratified according to sensitivity to endocrine therapy and the presence of visceral metastasis. Treatment continued until disease progression, intolerable toxicity, or withdrawal of consent. During the study, dose reductions or interruptions were allowed to manage AEs. Crossover from the PBO arm to the EVE arm was not allowed.

Study endpoints

The primary endpoint was PFS, defined as the time from randomization to the first documentation of disease progression (as assessed by the local investigator according to Response Evaluation Criteria in Solid Tumors [RECIST] [19] or, in the case of nonmeasurable disease, unequivocal progression or appearance of new lesions) or death from any cause. The key secondary endpoint was overall survival. Other secondary endpoints included overall response rate (ORR), clinical benefit rate (CBR), and time to overall response and duration of overall response according to RECIST [19].

\section{Efficacy and safety assessments}

An independent data monitoring committee (IDMC) was responsible for monitoring safety and pharmacokinetic data as well as reviewing efficacy results at the interim and final analyses. Tumor evaluation based on computed tomography or magnetic resonance imaging was performed at baseline (within 6 weeks before randomization) and every 6 weeks thereafter until disease progression and initiation of further anticancer therapy. Objective tumor response and disease progression were assessed per RECIST version 1.0 [19]. AEs were assessed at each study visit and were graded according to the National Cancer Institute Common Terminology Criteria for Adverse Events, version 3.0 [20].

\section{Patient-reported outcomes}

Quality of life (QOL) was evaluated using the European Organization for Research and Treatment of Cancer Quality of Life Questionnaire-Core 30 (EORTC QLQ-C30; Version 3.0, 2001), a reliable and valid questionnaire developed to assess the quality of life of cancer patients $[21,22]$. This self-administered questionnaire is composed of 30 items arranged into a number of functional and symptom subscales as well as a global health status (GHS)/ global QOL subscale, which was the primary QOL variable of interest for BOLERO-2.

Statistical analyses

Progression-free survival was based on the intent-to-treat analysis, according to the randomized treatment group and stratification. Distribution of PFS was estimated using the Kaplan-Meier method, and the HRs and corresponding $95 \%$ confidence intervals (CIs) were estimated using the Cox proportional hazard model. In addition, the protocolspecified time to definitive deterioration (TTD) in the EORTC QLQ-C30 GHS score (defined as a $5 \%$ decrease in QOL relative to baseline, with no subsequent increase above this threshold) was calculated in the Asian subset using Kaplan-Meier estimates and was described using medians and $95 \%$ CIs. The TTD was compared between $\mathrm{EVE}+\mathrm{EXE}$ and PBO + EXE using a log-rank test. 


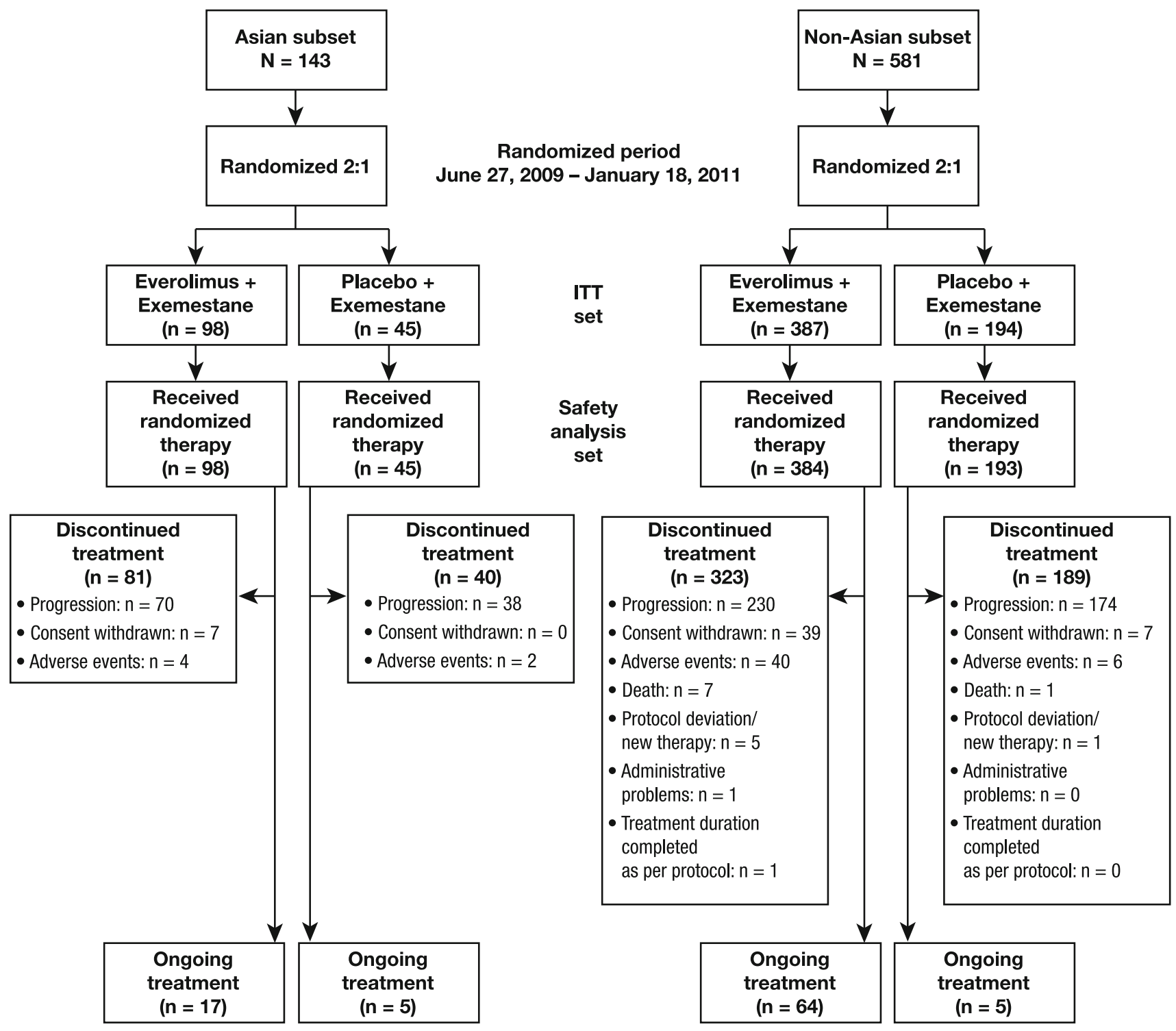

Fig. 1 CONSORT flowchart. ITT intention-to-treat. Ongoing treatment refers to those patients at time of cutoff for this analysis. Note that disease progression events in this figure are those that resulted in treatment discontinuation

\section{Results}

\section{Patient characteristics}

Median follow-up was 18 months at the time of this analysis (cutoff date 15 December 2011). Of the 724 patients in BOLERO-2, 143 were Asian, with 106 (74.1\%) of Japanese origin. There were 98 Asian patients in the EVE + EXE arm and 45 in the PBO + EXE arm (Fig. 1).

Patient and disease characteristics at baseline among the Asian and non-Asian patients were generally comparable, although the Asian patients were younger and a greater proportion had good performance status (Table 1). Among the Asian population, there were more patients in the $\mathrm{EVE}+\mathrm{EXE}$ arm who had at least 3 sites of metastases compared with the PBO + EXE arm. In the PBO + EXE arm, Asian patients had less visceral disease than non-Asian patients. Prior treatments at study entry were mostly similar between Asian and non-Asian patients. However, more nonAsian patients in the EVE + EXE arm received chemotherapy in the metastatic setting than Asian patients (Table 1).

The median durations of exposure to treatment were longer in Asian patients than in non-Asian patients. Among Asian patients, median exposure to EVE was 27.6 weeks, whereas median exposure to EXE was 32.6 weeks in the $\mathrm{EVE}+\mathrm{EXE}$ arm and 18.0 weeks in the PBO + EXE arm. Among non-Asian patients, median exposure to EVE was 23.7 weeks; median exposure to EXE was 28.1 weeks in the EVE + EXE arm and 13.9 weeks in the PBO + EXE arm (Table 2). 
Table 1 Demographics of Asian versus Non-Asian population

\begin{tabular}{|c|c|c|c|c|}
\hline \multirow[t]{2}{*}{ Baseline demographics } & \multicolumn{2}{|l|}{ Asian } & \multicolumn{2}{|l|}{ Non-Asian } \\
\hline & $\begin{array}{l}\text { Everolimus }+ \text { exemestane } \\
(n=98)\end{array}$ & $\begin{array}{l}\text { Placebo + exemestane } \\
(n=45)\end{array}$ & $\begin{array}{l}\text { Everolimus }+ \text { exemestane } \\
(n=387)\end{array}$ & $\begin{array}{l}\text { Placebo + exemestane } \\
(n=194)\end{array}$ \\
\hline \multicolumn{5}{|l|}{ Age, years } \\
\hline Mean (SD) & $59.9(7.2)$ & $58.6(8.2)$ & $63.1(10.9)$ & $61.8(10.0)$ \\
\hline Median (range) & $59.5(40.0-79.0)$ & $60.0(28.0-72.0)$ & $63.0(34.0-93.0)$ & $61.0(38.0-90.0)$ \\
\hline \multicolumn{5}{|l|}{ Age group, \% } \\
\hline$<65$ years & 77.6 & 82.2 & 55.3 & 62.9 \\
\hline$\geq 65$ years & 22.4 & 17.8 & 44.7 & 37.1 \\
\hline \multicolumn{5}{|l|}{ Ethnicity, \% } \\
\hline Chinese & 5.1 & 0 & 0 & 0 \\
\hline Japanese & 72.4 & 77.8 & 0 & 0 \\
\hline Mixed & 1.0 & 0 & 2.1 & 3.1 \\
\hline Hispanic/Latino & 0 & 0 & 7.2 & 5.2 \\
\hline Indian (subcontinent) & 0 & 0 & 0.3 & 0 \\
\hline Other & 21.4 & 22.2 & 90.4 & 91.8 \\
\hline \multicolumn{5}{|l|}{ Number of metastatic sites, $\%^{\mathrm{a}}$} \\
\hline 1 & 33.7 & 33.3 & 31.5 & 25.3 \\
\hline 2 & 22.4 & 33.3 & 32.6 & 35.6 \\
\hline$\geq 3$ & 42.8 & 33.3 & 35.7 & 39.2 \\
\hline \multicolumn{5}{|l|}{ ECOG performance status, $\%$} \\
\hline 0 & 82.7 & 86.7 & 54.8 & 53.1 \\
\hline 1 & 15.3 & 13.3 & 41.1 & 40.2 \\
\hline 2 & 0 & 0 & 2.3 & 3.6 \\
\hline \multicolumn{5}{|c|}{ Time between initial diagnosis and 1st recurrence/metastasis, $\%$} \\
\hline$<3$ months & 13.3 & 11.1 & 22.2 & 20.1 \\
\hline 3 to $<6$ months & 0 & 0 & 1.3 & 2.6 \\
\hline$\geq 6$ months & 80.6 & 80.0 & 69.3 & 71.6 \\
\hline Missing & 6.1 & 8.9 & 7.2 & 5.7 \\
\hline \multicolumn{5}{|l|}{ Metastatic cancer sites, $\%$} \\
\hline $\mathrm{CNS}^{\mathrm{b}}$ & 2.0 & 0 & 1.0 & 0 \\
\hline Visceral (excluding CNS) $^{\mathrm{c}}$ & 59.2 & 53.3 & 58.1 & 60.8 \\
\hline Lung & 34.7 & 31.1 & 28.2 & 33.5 \\
\hline Liver & 31.6 & 22.2 & 33.9 & 32.5 \\
\hline Lung and liver & 9.2 & 4.4 & 9.0 & 12.4 \\
\hline Bone & 69.4 & 51.1 & 78.3 & 83.5 \\
\hline Bone only & 20.4 & 11.1 & 22.0 & 21.1 \\
\hline Other & 56.1 & 73.3 & 49.1 & 53.6 \\
\hline \multicolumn{5}{|l|}{ Previous chemotherapy, \% } \\
\hline Adjuvant/neoadjuvant only & 60.2 & 48.9 & 39.5 & 37.6 \\
\hline Metastatic only & 6.1 & 11.1 & 15.8 & 9.3 \\
\hline Both & 10.2 & 15.6 & 12.4 & 16.0 \\
\hline \multicolumn{5}{|c|}{ Number of previous chemotherapy lines in advanced setting, $\%$} \\
\hline 1 & 16.3 & 26.7 & 28.2 & 23.7 \\
\hline 2 & 0 & 0 & 0 & 0 \\
\hline
\end{tabular}

Data from 15 December 2011 safety update cutpoint

$C N S$ central nervous system, ECOG Eastern Cooperative Oncology Group, SD standard deviation

a One patient each in the Asian and non-Asian subgroups had missing information

b CNS includes spinal cord, brain and meninges

${ }^{c}$ Visceral includes lung, liver, pleural, pleural effusions, peritoneum, and ascites 
The percentages of patients who required EVE dose reductions or interruptions were similar between the Asian and non-Asian patients $(71.4$ vs. $65.6 \%)$, as were the percentages of Asian and non-Asian patients who required EXE dose reductions or interruptions while receiving EVE + EXE (22.4 vs. $24.2 \%$ ), respectively. In contrast, Asian patients receiving PBO + EXE required more EXE dose reductions or interruptions than non-Asian patients (26.7 vs. $8.3 \%$ ), respectively. Most of these dose reductions or interruptions were the result of an $\mathrm{AE}$ (data not shown). At the time of cutoff, $15.4 \%$ of Asian patients and $11.9 \%$ of non-Asian patients were ongoing with study treatment (Fig. 1). Among Asian patients, $82.7 \%$ discontinued EVE + EXE treatment and $88.9 \%$ discontinued PBO + EXE treatment, whereas 83.5 and $97.4 \%$ of nonAsian patients discontinued EVE + EXE and PBO + EXE treatment, respectively (Fig. 1). Most of the patients who discontinued treatment did so because of disease progression.

\section{Efficacy}

The combination of EVE and EXE reduced the risk of disease progression by $38 \%$ among Asian patients compared with $\mathrm{PBO}+\mathrm{EXE}(\mathrm{HR}=0.62 ; 95 \% \mathrm{CI}, 0.41-0.94$; Fig. 2). At the cutoff date, $17.3 \%$ of Asian patients in the EVE + EXE arm and $11.1 \%$ of patients in the PBO + EXE arm were progression free and remained on treatment, whereas $71.4 \%$ of Asian patients in the EVE + EXE arm and $84.4 \%$ of patients in the PBO + EXE arm had disease progression (Fig. 1). Median PFS per local investigator assessment among Asian patients in BOLERO-2 was 8.48 months for EVE + EXE versus 4.14 months for $\mathrm{PBO}+$ EXE (Fig. 2).

Japanese patients comprised the largest subset within the Asian subgroup, and nearly $15 \%$ of the overall BOLERO2 patient population. Therefore, additional analyses specific to the Japanese subset were feasible, and indicated that treatment with EVE + EXE significantly improved median PFS versus PBO + EXE by $42 \%(\mathrm{HR}=0.58)$ in these patients. The median PFS results also favored the combination of everolimus and exemestane in European and North American patients (Fig. 3).

There were no complete responses (CRs) recorded for either the EVE + EXE or the PBO + EXE arm. No partial responses (PRs) were observed with $\mathrm{PBO}+\mathrm{EXE}$ in the Asian subset, compared with 19 PRs $(19.4 \%)$ in the EVE + EXE arm based on local investigator assessment. Overall, Asian patients had greater CBR and ORR in the EVE + EXE arm than in the PBO + EXE arm (CBR, 58.2 vs. $28.9 \%$; ORR, $19.4 \%$ vs. 0, respectively; Table 3).

For non-Asian patients, the median PFS per investigator assessment in the 2 arms was 7.33 months and 2.83 months, respectively $(\mathrm{HR}=0.41 ; 95 \% \mathrm{CI}, 0.33-0.50$; Table 3 , Fig. 2). Based on local investigator assessment, there were 3 CRs and 39 PRs (10.1\%) among non-Asian patients in the EVE + EXE arm versus no CRs and 4 PRs in the PBO + EXE arm. The CBR and ORR for non-Asian patients were 49.6 and $10.9 \%$ in the combination arm versus 25.8 and $2.1 \%$ in the PBO + EXE arm, respectively (Table 3).

Safety

Across the entire study, the most common treatment-emergent AEs in the EVE + EXE arm included stomatitis and rash; these were also the most common AEs among both Asian and non-Asian patients (Table 4) [15]. Some AEs were reported in a higher percentage of Asian patients compared with the non-Asian patients. These included stomatitis, rash, dysgeusia, pneumonitis, nail disorder, increased LDH, nasopharyngitis, and ILD. Specifically, the rates of grade 1 and 2 dysgeusia were higher in Asian versus non-Asian patients in the EVE + EXE arm (30.6 vs. $19.8 \%$ ) but comparable in the PBO + EXE arm (6.7 vs. $5.7 \%)$. The incidence of nasopharyngitis was similar across treatment arms, but much higher in Asian than non-Asian patients in both the EVE + EXE (22.4 vs. $7.0 \%)$ and PBO + EXE (20.0 vs. $6.2 \%$ ) arms; all events were grades 1 or 2 (Table 4). Pneumonitis, which was reported only in the EVE + EXE arm, was higher in Asian patients than in non-Asian patients in the EVE + EXE arm (23.5 vs. $14.1 \%$, respectively). However, the frequency of grade 3 and 4 pneumonitis was

Table 2 Duration of exposure to study treatment

\begin{tabular}{|c|c|c|c|c|c|c|c|c|}
\hline & \multicolumn{4}{|c|}{ Asian patients } & \multicolumn{4}{|c|}{ Non-Asian patients } \\
\hline & \multicolumn{2}{|c|}{$\begin{array}{l}\text { Everolimus }+ \text { exemestane } \\
(n=98)\end{array}$} & \multicolumn{2}{|c|}{$\begin{array}{l}\text { Placebo + exemestane } \\
(n=45)\end{array}$} & \multicolumn{2}{|c|}{$\begin{array}{l}\text { Everolimus }+ \text { exemestane } \\
(n=384)\end{array}$} & \multicolumn{2}{|c|}{$\begin{array}{l}\text { Placebo }+ \text { exemestane } \\
(n=193)\end{array}$} \\
\hline & Everolimus & Exemestane & Placebo & Exemestane & Everolimus & Exemestane & Placebo & Exemestane \\
\hline \multicolumn{9}{|c|}{ Duration (weeks) } \\
\hline Median & 27.6 & 32.6 & 18.0 & 18.0 & 23.7 & 28.1 & 13.1 & 13.9 \\
\hline Range & $2.0-123.3$ & $2.0-123.3$ & $2.0-101.0$ & $4.0-101.0$ & $1.0-109.4$ & $1.0-109.4$ & $1.0-82.0$ & $1.0-82.0$ \\
\hline
\end{tabular}


Fig. 2 Kaplan-Meier analyses of progression-free survival in a Asian and $\mathbf{b}$ non-Asian patients with advanced breast cancer. $C I$ confidence interval, EVE everolimus, EXE exemestane, $H R$ hazard ratio, $P B O$ placebo
Fig. 3 Forest plot of progression-free survival subgroup analysis by region and ethnicity. Subsets were prespecified in the analysis plan. Data from 18-months' median follow-up. $E V E$ everolimus, EXE exemestane, $H R$ hazard ratio, $P B O$ placebo, $P F S$ progression-free survival

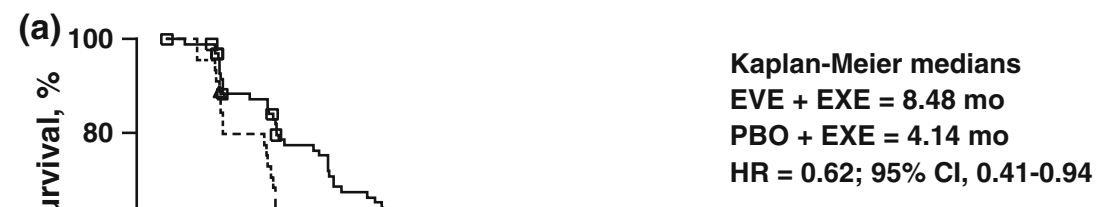

$\mathrm{HR}=0.62 ; 95 \% \mathrm{Cl}, 0.41-0.94$

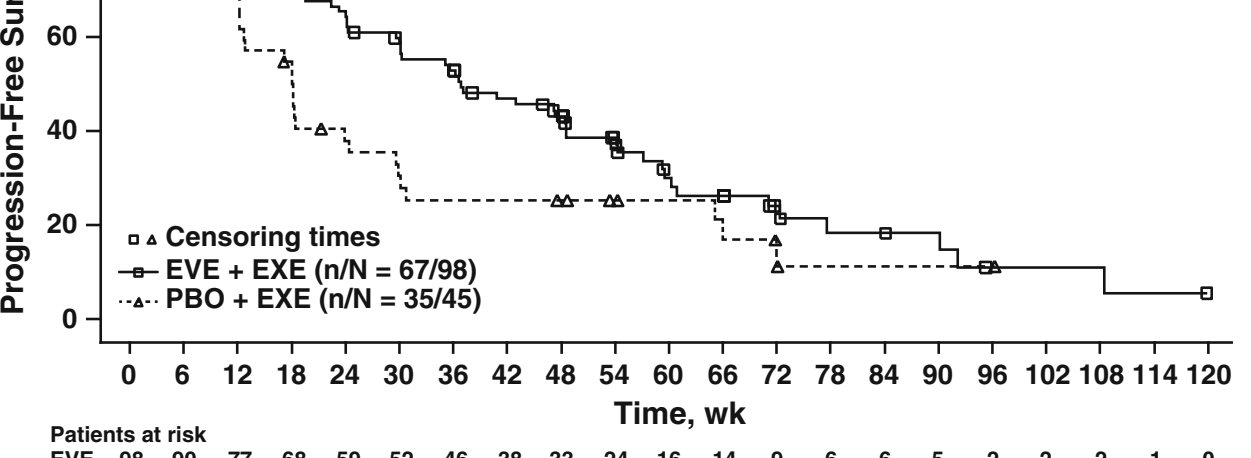
$\begin{array}{llllllllllllllllllllll}\text { EVE } & 98 & 90 & 77 & 68 & 59 & 52 & 46 & 38 & 33 & 24 & 16 & 14 & 9 & 6 & 6 & 5 & 2 & 2 & 2 & 1 & 0 \\ \text { PBO } & 45 & 41 & 31 & 23 & 15 & 12 & 10 & 10 & 9 & 7 & 6 & 5 & 3 & 1 & 1 & 1 & 1 & 0 & 0 & 0 & 0\end{array}$

(b)

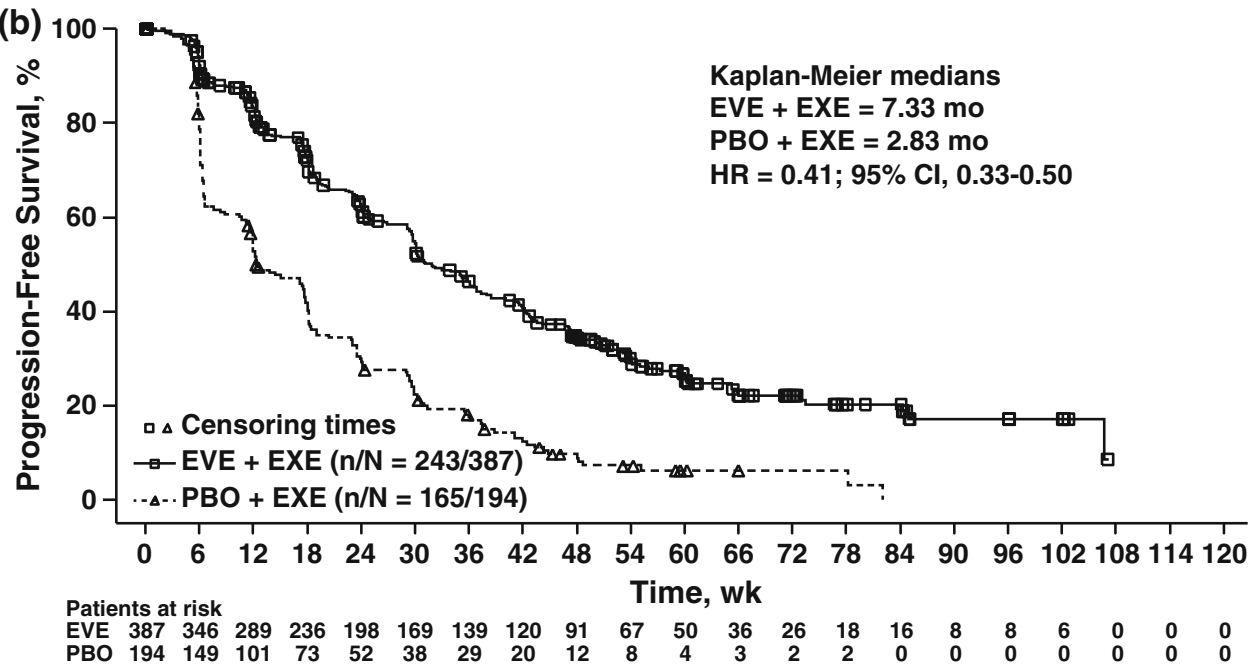

lower in Asian patients compared with non-Asian patients (2.0 vs. $3.6 \%$, respectively). In contrast, hot flushes were comparable in incidence between Asian and non-Asian

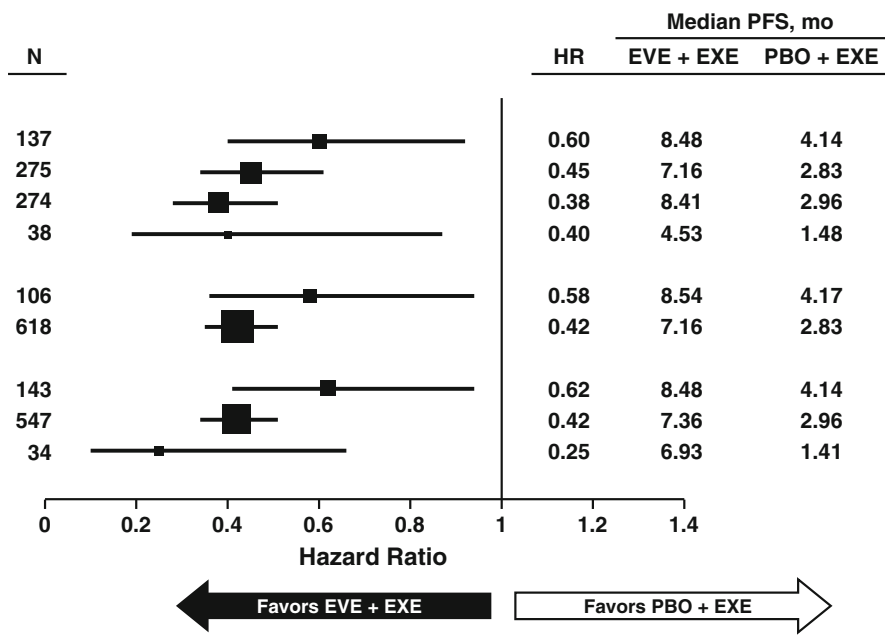

patients. They were, however, less frequent in Asian and nonAsian patients in the EVE + EXE arm (6.1 and 5.5\%) than in the PBO + EXE arm (13.3 and $14.5 \%$ ) (Table 4). 
Table 3 Best response

\begin{tabular}{|c|c|c|c|c|}
\hline & \multicolumn{2}{|l|}{ Asian } & \multicolumn{2}{|l|}{ Non-Asian } \\
\hline & $\begin{array}{l}\text { Everolimus + exemestane } \\
(n=98)\end{array}$ & $\begin{array}{l}\text { Placebo }+ \text { exemestane } \\
(n=45)\end{array}$ & $\begin{array}{l}\text { Everolimus }+ \text { exemestane } \\
(n=387)\end{array}$ & $\begin{array}{l}\text { Placebo + exemestane } \\
(n=194)\end{array}$ \\
\hline \multicolumn{5}{|l|}{ Best overall response, $\%$} \\
\hline Complete & 0 & 0 & $<1$ & 0 \\
\hline Partial & 19 & 0 & 10 & 2 \\
\hline Stable disease & 66 & 78 & 73 & 55 \\
\hline Progressive disease & 11 & 20 & 10 & 36 \\
\hline Unknown & 3 & 2 & 7 & 8 \\
\hline Objective response rate, $\%^{\mathrm{a}}$ & 19 & 0 & 11 & 2 \\
\hline Clinical benefit rate, $\%^{\mathrm{b}}$ & 58 & 29 & 50 & 26 \\
\hline
\end{tabular}

Notably, the incidence of grade 3 and 4 AEs among patients who received EVE + EXE was generally similar or lower in Asian patients compared with non-Asian patients (Table 4). The only exceptions were increased aspartate aminotransferase (AST) levels and cough. The most common grade 3 and 4 AEs $(\geq 5 \%$ ) for both Asian and non-Asian patients in the EVE $+\mathrm{EXE}$ treatment group included stomatitis (8.2 vs. $7.8 \%$ ), anemia (7.1 vs. $7.6 \%$ ), increased AST levels (6.1 vs. $2.9 \%$ ), hyperglycemia (4.1 vs. $6.0 \%$ ), and dyspnea (3.1 vs. $5.7 \%$ ), respectively. There were very few grade 4 AEs reported, regardless of treatment arm or ethnicity subset, and none were reported in at least $5 \%$ of the patients studied (Table 4 ).

Quality of life in Asian patients

Treatment with EVE + EXE did not affect TTD in EORTC QLQ-C30 GHS compared with PBO + EXE in Asian patients. At the protocol-defined threshold of $5 \%$ decrease from baseline, the median TTD was 8.4 months (95\% CI, 6.9-11.1 months) in the EVE + EXE arm compared with 5.6 months (95\% CI, 2.9-15.2 months) in the $\mathrm{PBO}+\mathrm{EXE} \operatorname{arm}(\mathrm{HR}=0.79 ; 97.5 \% \mathrm{CI}, 0.44-1.44 ;$ Fig. 4).

\section{Discussion}

Although women with $\mathrm{HR}^{+}$breast cancer often respond to multiple lines of endocrine therapy, most ultimately progress. When patients with $\mathrm{HR}^{+}$advanced breast cancer progress despite nonsteroidal aromatase inhibitors, the current treatment paradigm includes EXE followed by tamoxifen, toremifene, or fulvestrant [4]. This paradigm is followed in Asia as well as in Western countries. Once patients progress on initial endocrine therapy, the available treatment options offer limited clinical benefit and poor survival [5]. New treatment options are needed that can offer patients with advanced breast cancer the hope of overcoming resistance, prolong the time for which endocrine therapy is effective, and delay chemotherapy.

In the phase 3 BOLERO-2 study, the addition of EVE to EXE increased median PFS by 4.6 months [12]. These results suggest that inhibition of cross-talk pathways (PI3K/mTOR) may help improve outcomes in this patient population. Nearly $20 \%$ of the 724 patients in this study were Asian, providing an opportunity to determine the efficacy and safety of EVE in this important subgroup.

Ethnic differences can account for variations in both the pharmacokinetics and pharmacodynamics of anticancer agents, potentially resulting in alterations of the safety and efficacy profiles of these agents [13]. For example, docetaxel, like gefitinib [15], has demonstrated enhanced efficacy in Asian versus Caucasian patients [13]. This was accompanied, however, by higher incidence of febrile neutropenia requiring hospitalization [13]. CYP2D6 genetic polymorphisms have been shown to affect the conversion of tamoxifen to its most active metabolite, endoxifen. As a result, the efficacy of tamoxifen might vary according to the distribution of these genetic polymorphisms among various ethnic populations [13]. The distribution of genetic polymorphisms affecting CYP2D6 activity is different between Asian and non-Asian patients. Thus, it is hypothesized that the efficacy of tamoxifen may also be different between these patient populations [13]. To ensure optimal treatment response and understand the safety profile, it is important to consider the potential interethnic differences in anticancer drug effects [13].

We have demonstrated in this report that the efficacy of EVE is consistent between the Asian and non-Asian subgroups. Combining EVE with EXE more than doubled the median PFS versus EXE with PBO, from 4.14 to 8.48 months for Asians and from 2.83 to 7.33 months for 
Table 4 Treatment-emergent adverse events with at least $10 \%$ incidence in the everolimus + exemestane arm in the Asian and non-Asian subpopulations

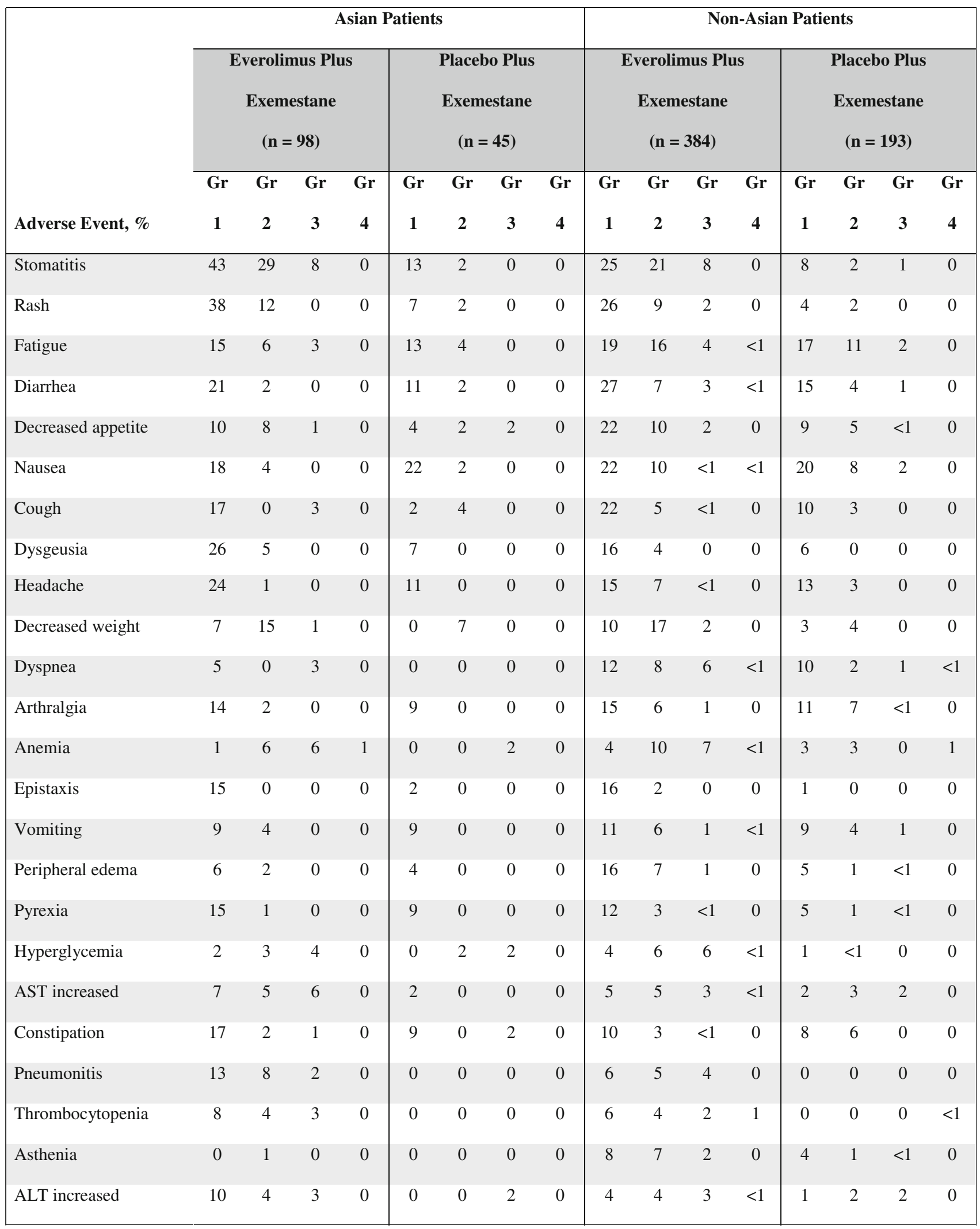


Table 4 continued

\begin{tabular}{|c|c|c|c|c|c|c|c|c|c|c|c|c|c|c|c|c|}
\hline & & & & sian & atien & & & & & & & -Asic & Pat & & & \\
\hline & & ero & $\begin{array}{l}\text { us I } \\
\text { stan } \\
\text { 98) }\end{array}$ & & & $\begin{array}{l}\text { Place } \\
\text { Exen } \\
\text { (n }\end{array}$ & $\begin{array}{l}\text { Plu } \\
\text { stan } \\
\text { 45) }\end{array}$ & & & $\begin{array}{l}\text { erol } \\
\text { ExeI } \\
\text { (n }\end{array}$ & $\begin{array}{l}\text { Ius I } \\
\text { stan } \\
\text { 384) }\end{array}$ & & & $\begin{array}{l}\text { Place } \\
\text { Exen } \\
\text { (n }=\end{array}$ & $\begin{array}{l}\text { Plu } \\
\text { stant } \\
\text { 193) }\end{array}$ & \\
\hline & $\mathbf{G r}$ & Gr & Gr & Gr & $\mathbf{G r}$ & $\mathbf{G r}$ & $\mathbf{G r}$ & Gr & $\mathbf{G r}$ & $\mathbf{G r}$ & Gr & $\mathbf{G r}$ & Gr & Gr & $\mathbf{G r}$ & $\mathbf{G r}$ \\
\hline Adverse Event, \% & 1 & 2 & 3 & 4 & 1 & 2 & 3 & 4 & $\mathbf{1}$ & 2 & 3 & 4 & 1 & 2 & 3 & 4 \\
\hline Pruritus & 10 & 2 & 0 & 0 & 4 & 2 & 0 & 0 & 11 & 3 & $<1$ & 0 & 3 & 2 & 0 & 0 \\
\hline Insomnia & 10 & 2 & 1 & 0 & 4 & 0 & 0 & 0 & 10 & 4 & 0 & 0 & 6 & 3 & 0 & 0 \\
\hline Back pain & 9 & 2 & 0 & 0 & 4 & 0 & 0 & 0 & 10 & 6 & $<1$ & 0 & 6 & 4 & 2 & 0 \\
\hline Dry mouth & 3 & 0 & 0 & 0 & 2 & 0 & 0 & 0 & 12 & 2 & 0 & 0 & 8 & $<1$ & 0 & 0 \\
\hline Alopecia & 5 & 0 & 0 & 0 & 2 & 0 & 0 & 0 & 10 & 1 & 0 & 0 & 6 & 0 & 0 & 0 \\
\hline Pain in extremity & 4 & 1 & 0 & 0 & 0 & 4 & 0 & 0 & 7 & 3 & $<1$ & 0 & 6 & 5 & 2 & 0 \\
\hline GGT increased & 1 & 2 & 4 & 0 & 0 & 0 & 2 & 0 & 2 & 2 & 5 & 2 & 1 & 1 & 5 & 3 \\
\hline Hypercholesterolemia & 4 & 4 & 0 & 0 & 0 & 0 & 0 & 0 & 7 & 3 & $<1$ & $<1$ & 1 & 0 & 0 & 0 \\
\hline Nasopharyngitis & 21 & 1 & 0 & 0 & 20 & 0 & 0 & 0 & 6 & 1 & 0 & 0 & 4 & 3 & 0 & 0 \\
\hline Nail disorder & 21 & 1 & 0 & 0 & 0 & 0 & 0 & 0 & 4 & $<1$ & 0 & 0 & $<1$ & 0 & 0 & 0 \\
\hline Hot flush & 6 & 0 & 0 & 0 & 13 & 0 & 0 & 0 & 5 & $<1$ & 0 & 0 & 10 & 5 & 0 & 0 \\
\hline LDH increased & 12 & 1 & 1 & 0 & 2 & 0 & 0 & 0 & 2 & 2 & 0 & 0 & 0 & 2 & 0 & 0 \\
\hline ILD & 8 & 4 & 1 & 0 & 0 & 0 & 0 & 0 & 0 & $<1$ & $<1$ & 0 & 0 & 0 & 0 & 0 \\
\hline
\end{tabular}

$A L T$ alanine aminotransferase, $A S T$ aspartate aminotransferase, $G G T$ gamma-glutamyltransferase, $I L D$ interstitial lung disease, $L D H$ lactate dehydrogenase

non-Asians. Asian patients also experienced a greater CBR and ORR after receiving EVE + EXE versus PBO + EXE. Median exposure to EVE + EXE was nearly 4 weeks longer in Asian versus non-Asian patients. Despite the longer exposure to EVE + EXE in Asian patients, the frequency of drug discontinuation for these patients was lower than for non-Asian patients. Also, there were no significant differences in TTD of EORTC QLQ-C30 GHS for the Asian subset of patients. Finally, treatment-emergent AEs were comparable across the two groups.

Some AEs (e.g., stomatitis, nasopharyngitis, pneumonitis, and ILD) were slightly more frequently reported among Asian patients. Others (e.g., anemia) were less frequent. However, all AEs were generally consistent with those reported for EVE in the overall BOLERO-2 study [16]. Similar AEs were seen in other indications following EVE treatment [23]. Occurrences of grade 3 and 4 anemia, stomatitis, abnormal liver enzymes, fatigue, and hyperglycemia have also been frequently reported in Japanese patients with metastatic gastric cancer treated with EVE monotherapy following progression on chemotherapy [24]. Effective management of AEs associated with the use of EVE requires patient education, physician awareness, and early intervention [16]. In some cases (e.g., more severe instances or higher grades of these AEs), dose modifications and standard care have proven useful $[12,25]$.

Interstitial lung disease (ILD; characterized by the inflammation of the interstitium of the lung) and noninfectious pneumonitis (characterized by the presence of non-infectious, nonmalignant infiltrates) are known side effects of mTOR inhibitors [26, 27]. In the current study, AEs including ILD and non-infectious pneumonitis were coded using the MedDRA terminology (version 14.0) and were assessed as described in the "Methods" section. An 
Fig. 4 Time to deterioration in EORTC QLQ-C30 (5\% decrease from baseline). $C I$ confidence interval, EORTC $Q L Q$-C3O European

Organization for Research and Treatment of Cancer Quality of Life Questionnaire-Core 30, EVE everolimus, EXE exemestane, $P B O$ placebo, $T T D$ time to definitive deterioration

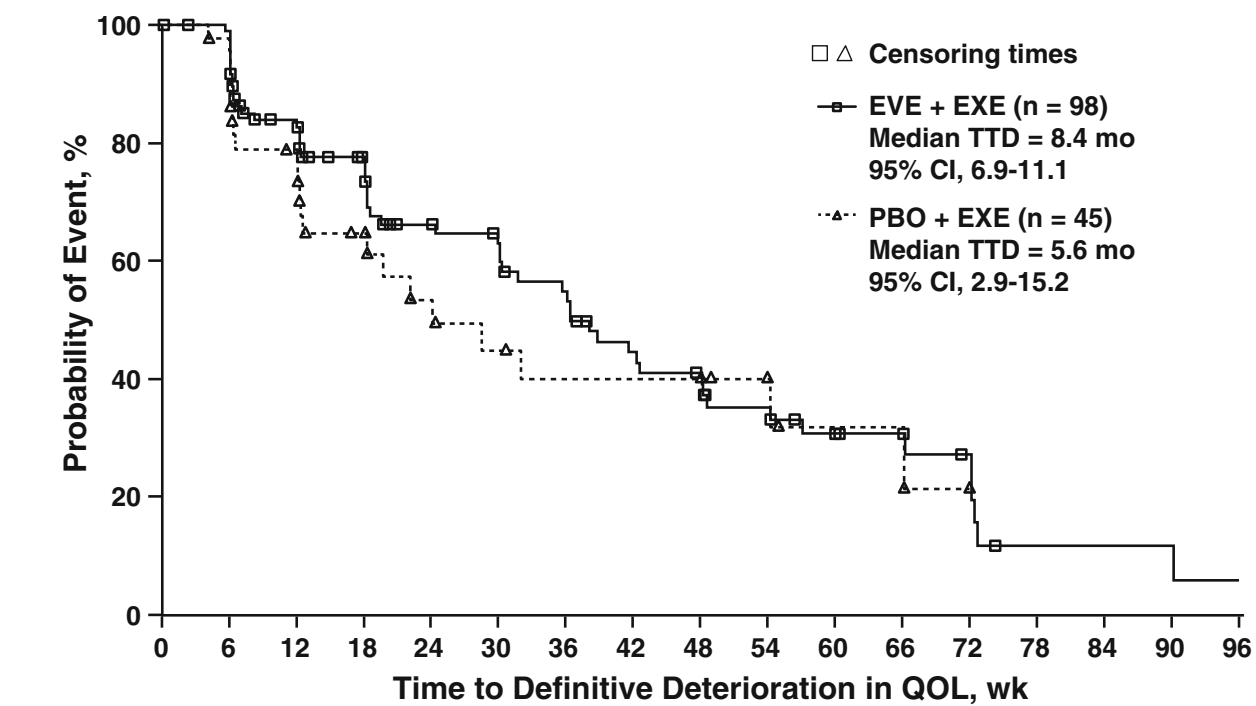

No. of patients still at risk

$\begin{array}{llllllllllllllllll}\text { EVE + EXE } & 98 & 94 & 69 & 55 & 43 & 40 & 33 & 25 & 22 & 17 & 13 & 10 & 7 & 2 & 2 & 2 & 1\end{array}$

increased frequency of ILD has been reported in Japanese cancer patients receiving molecular targeted anticancer therapies such as gefitinib and erlotinib [15]. The patterns of ILD were also the focus of a recent study that retrospectively evaluated 7 Japanese patients treated with EVE for advanced renal cell carcinoma [28]. Patients with mild ILD were able to continue EVE treatment. More severe ILD led to EVE discontinuation and short-term steroid therapy, which generally resulted in rapid resolution of ILD. Prompt recognition of ILD incidence or exacerbation, and exclusion of progressive disease or infection, were determined to be of paramount importance for the successful management of these AEs [28]. The frequency of ILD overall was higher in the Asian patients in this BOLERO-2 study; nonetheless, grade 3 and 4 ILD occurred with similar low frequencies in Asian and non-Asian patients. Whereas pneumonitis, like ILD, was more prevalent in Asian patients treated with EVE + EXE, some of the symptoms of pneumonitis, such as dyspnea and cough, were less frequent in the Asian patients in the EVE + EXE arm. This demonstrates that EVE treatment is not associated with any exacerbated safety concerns based on patient ethnicity.

In conclusion, combining EVE with EXE provided substantial clinical benefit to both Asian and non-Asian patients. EVE was well tolerated and most of the EVE-related AEs were manageable. Observed AEs in BOLERO-2 were consistent with AEs previously reported for rapamycin analogues $[29,30]$. This combination of EVE + EXE did not affect selfassessed QOL in Asian patients. Thus, EVE + EXE represents an important improvement in the management of postmenopausal women with $\mathrm{HR}^{+} \mathrm{HER}^{-}$advanced breast cancer progressing after nonsteroidal aromatase inhibitor treatment, regardless of ethnicity.
Acknowledgments The BOLERO-2 trial was supported by Novartis Pharmaceuticals: ClinicalTrials.gov identifier NCT00863655. Funding for medical editorial support was also provided by Novartis. Financial support for medical editorial assistance was provided by Novartis Pharmaceuticals. We thank Kristin E. Larsen, PhD, ProEd Communications, Inc., for medical editorial assistance with this manuscript. The BOLERO-2 trial was conducted in the USA, Japan, Canada, Brazil, Austria, Belgium, Czech Republic, France, Germany, Hungary, Italy, the Netherlands, Norway, Poland, Spain, Sweden, Turkey, UK, Egypt, Australia, China (Hong Kong), New Zealand, South Korea, and Thailand. We thank the patients, study site personnel, and the study team for their participation in the trial.

Conflict of interest S. Noguchi has received research funding from and has been an advisor for Novartis; N. Masuda, H. Mukai, J. Horiguchi, P. Puttawibul, V. Srimuninnimit, K. Kuroi, H. Inaji, S. Ohsumi, W. Noh, T. Nakayama, S. Ohno, Y. Rai, B. Park, and Y. Ito have nothing to disclose; $H$. Iwata has received honoraria from Novartis, Chugai, and AstraZeneca; Y. Tokuda and H. Iwase have received research funding from Novartis; A. Panneerselvam, T. Taran, and T. Sahmoud are employees of Novartis; M. El-Hashimy is an employee of and owns stock in Novartis.

Open Access This article is distributed under the terms of the Creative Commons Attribution License which permits any use, distribution, and reproduction in any medium, provided the original author(s) and the source are credited.

\section{References}

1. American Cancer Society. Global cancer facts \& figures. 2nd ed. Atlanta: American Cancer Society; 2011.

2. WHO. World Health Organization fact sheet no 297. Feb 2012. http://www.who.int/mediacentre/factsheets/fs297/en/index.html. Accessed 19 Mar 2012.

3. Althuis MD, Dozier JM, Anderson WF, Devesa SS, Brinton LA. Global trends in breast cancer incidence and mortality 1973-1997. Int J Epidemiol. 2005;34:405-12. 
4. National Comprehensive Cancer Network. NCCN Clinical Practice Guidelines in Oncology: Breast Cancer. Version I.2012. Available at: http://www.ncen.org/professionals/physician_gls/ pdf/breast.pdf. Accessed 19 Mar 2012.

5. Dodwell D, Wardley A, Johnston S. Postmenopausal advanced breast cancer: options for therapy after tamoxifen and aromatase inhibitors. Breast. 2006;15:584-94.

6. Miller TW, Hennessy BT, Gonzalez-Angulo AM, et al. Hyperactivation of phosphatidylinositol-3 kinase promotes escape from hormone dependence in estrogen receptor-positive human breast cancer. J Clin Invest. 2010;120:2406-13.

7. Meric-Bernstam F, Chen H, Akcakanat A, et al. Aberrations in translational regulation are associated with poor prognosis in hormone receptor-positive breast cancer. Presented at the American Association for Cancer Research annual meeting; 2012; Chicago, Illinois, USA. Abstract CT-03.

8. Beeram M, Tan QT, Tekmal RR, et al. Akt-induced endocrine therapy resistance is reversed by inhibition of mTOR signaling. Ann Oncol. 2007;18:1323-8.

9. Boulay A, Rudloff J, Ye J, et al. Dual inhibition of mTOR and estrogen receptor signaling in vitro induces cell death in models of breast cancer. Clin Cancer Res. 2005;11:5319-28.

10. deGraffenried LA, Friedrichs WE, Russell DH, et al. Inhibition of mTOR activity restores tamoxifen response in breast cancer cells with aberrant Akt activity. Clin Cancer Res. 2004;10:8059-67.

11. Ghayad SE, Bieche I, Vendrell JA, et al. mTOR inhibition reverses acquired endocrine therapy resistance of breast cancer cells at the cell proliferation and gene-expression levels. Cancer Sci. 2008;99:1992-2003.

12. Novartis Pharmaceuticals Corporation. Afinitor (everolimus) prescribing information. East Hanover, NJ, Novartis, 2012. http://www.pharma.us.novartis.com/product/pi/pdf/afinitor.pdf.

13. Ling WH, Lee SC. Inter-ethnic differences-how important is it in cancer treatment? Ann Acad Med Singapore. 2011;40:356-61.

14. Xie HG, Kim RB, Wood AJ, Stein CM. Molecular basis of ethnic differences in drug disposition and response. Annu Rev Pharmacol Toxicol. 2001;41:815-50.

15. Sekine I, Yamamoto N, Nishio K, Saijo N. Emerging ethnic differences in lung cancer therapy. Br J Cancer. 2008;99:1757-62.

16. Baselga J, Campone M, Piccart M, et al. Everolimus in postmenopausal hormone-receptor-positive advanced breast cancer. N Engl J Med. 2012;366:520-9.

17. Okamoto I, Doi T, Ohtsu A, et al. Phase I clinical and pharmacokinetic study of RAD001 (everolimus) administered daily to Japanese patients with advanced solid tumors. Jpn J Clin Oncol. 2010;40:17-23.

18. Hortobagyi GN, Piccart M, Rugo H, et al. Everolimus for postmenopausal women with advanced breast cancer: Updated results of the BOLERO-2 phase III trial. Presented at the 34th Annual CTRC-AACR San Antonio Breast Cancer Symposium (SABCS). San Antonio, Texas; 6-10 Dec 2011. Abstract S3-7.

19. Therasse P, Arbuck SG, Eisenhauer EA, et al. New guidelines to evaluate the response to treatment in solid tumors. European Organization for Research and Treatment of Cancer, National Cancer Institute of the United States, National Cancer Institute of Canada. J Natl Cancer Inst. 2000;92:205-16.

20. National Cancer Institute. Common Terminology Criteria for Adverse Events v3.0 (CTCAE). Available at: http://ctep.cancer. gov/protocolDevelopment/electronic_applications/docs/ctcaev3. pdf. Accessed 24 Jan 2012.

21. Aaronson NK, Ahmedzai S, Bergman B, et al. The European Organization for Research and Treatment of Cancer QLQ-C30: a quality-of-life instrument for use in international clinical trials in oncology. J Natl Cancer Inst. 1993;85:365-76.

22. Fayers PM, Aaronson NK, Bjordal K, Groenvold M, Curran D, Bottomley A, on behalf of the EORTC Quality of Life Group. The EORTC QLQ-C30 Scoring Manual. 3rd ed. Brussels: European Organisation for Research and Treatment of Cancer; 2001.

23. Porta C, Osanto S, Ravaud A, et al. Management of adverse events associated with the use of everolimus in patients with advanced renal cell carcinoma. Eur J Cancer. 2011;47:1287-98.

24. Doi T, Muro K, Boku N, et al. Multicenter phase II study of everolimus in patients with previously treated metastatic gastric cancer. J Clin Oncol. 2010;28:1904-10.

25. Tsukamoto T, Shinohara N, Tsuchiya N, et al. Phase III trial of everolimus in metastatic renal cell carcinoma: subgroup analysis of Japanese patients from RECORD-1. Jpn J Clin Oncol. 2011;41:17-24.

26. Oberstein PE, Saif MW. Safety and efficacy of everolimus in adult patients with neuroendocrine tumors. Clin Med Insights Oncol. 2012;6:41-51.

27. White DA, Camus P, Endo M, et al. Noninfectious pneumonitis after everolimus therapy for advanced renal cell carcinoma. Am J Respir Crit Care Med. 2010;182:396-403.

28. Mizuno R, Asano K, Mikami S, et al. Patterns of interstitial lung disease during everolimus treatment in patients with metastatic renal cell carcinoma. Jpn J Clin Oncol. 2012;42:442-6.

29. Chow LWC, Sun Y, Jassem J, et al. Phase 3 study of temsirolimus with letrozole or letrozole alone in postmenopausal women with locally advanced or metastatic breast cancer. Breast Cancer Res Treat. 2006;100 Suppl 1:S286. Abstract 6091.

30. Motzer RJ, Escudier B, Oudard S, et al. Phase 3 trial of everolimus for metastatic renal cell carcinoma: final results and analysis of prognostic factors. Cancer. 2010;116:4256-65. 